\title{
Travessias da aula em campo na geografia escolar: a necessidade convertida para além da fábula
}

Christian Dennys Monteiro de Oliveira

Raimundo Jucier Sousa de Assis

Universidade Federal do Ceará

\section{Resumo}

0 ensino de geografia cultiva um vínculo de identidade com o mundo exterior: a aula em campo. Os desafios para investigação escolar das instituições, localidades e relações são enormes. Esse exercício didático é o alvo do presente texto, cujo objetivo é mostrar a preocupação e o avanço, de alguns estudiosos, na construção de uma 'teoria' das aulas de campo, aqui denominadas aulas em campo. A proposta corresponde à apresentação e discussão de certas abordagens específicas para esse tipo de aula. No entanto, esse cultivo não se realiza de forma contínua nem está no centro do planejamento da geografia escolar. Ele aparece como uma exceção contra a qual os autores aqui citados reagem, caracterizam limites e potencialidades e direcionam soluções. Para tanto, propõem seu resgate nas diversas formas de atividades externas ao espaço escolar: excursões, visitas, estudos do meio, turismo. A força pedagógica da aula em campo encontra-se, todavia, na capacidade da interação professor-aluno em apreender com o lugarmundo e planejar-se no improviso, o que, na conclusão do artigo, aparece como defesa de uma postura estratégica da gestão do retorno à sala de aula. Chamada de autobiografia coletiva da aula anterior, o texto propõe ampliar a relevância das discussões sobre a experiência do campo para potencializar os conteúdos e métodos de aprendizagem, lembrando que a aula em campo é, tal qual inspiração artística, um vetor insubstituível de compreensão do espaço em nível escolar.

\section{Palavras-chave}

Aula em campo - Geografia escolar - Trabalho de campo - Meio.

\footnotetext{
Correspondência:
}

Christian Dennys Monteiro de Oliveira

Departamento de Geografia - Campus

do Pici - Bloco 911

60455-760 - Fortaleza - CE

e-mail: cdm049@yahoo.com.br 


\title{
The excursions of the class in the field in school geography: the need converted beyond the fable
}

\author{
Christian Dennys Monteiro de Oliveira \\ Raimundo Jucier Sousa de Assis \\ Universidade Federal do Ceará
}

\begin{abstract}
The teaching of geography cultivates a link of identity with the exterior world: the field class. The challenges to the school investigation of institutions, localities and relations are huge. That didactic exercise is the subject of the present text, whose purpose is to show the concerns and progresses by some scholars in the construction of a "theory" of field classes, here denominated classes in the field. The proposal consists in presenting and discussing specific approaches to this kind of classes. However, this cultivation does not happen continuously, and is not at the heart of the planning of school geography. It shows up as an exception, a situation decried by these authors, who characterize limitations and potentialities and point to solutions. For that, they propose the revival of this idea within the various forms that activities external to the school take: excursions, visits, environmental studies, tourism. The pedagogical strength of the class in the field resides, however, in the potential of the teacher-student interaction for apprehending with the world, and for planning itself as it goes, resulting, in the conclusion to this article, in a defense of a strategic posture towards the management of the return to the classroom. Under the title of collective autobiography of the previous class, this text proposes to extend the relevance of the discussions about the field experience to fertilize contents and learning methods, recalling that the class in the field is, like an artistic inspiration, an irreplaceable element in the understanding of the space at the level of the school.
\end{abstract}

\section{Keywords}

Class in the field - School geography - Fieldwork - Environment. 
Não é no silêncio que os homens se fazem, mas na palavra, no trabalho, na ação-reflexiva.

Paulo Freire

0 bojo da discussão aqui proposta (transforma um conjunto multifacetado de temas aparentemente dispares, como educação formal (escolar) e educação cotidiana (que produzimos e somos produzidos); educação geográfica e espaço geográfico; formação do professor e formação do estudante; em um discurso dialético e dinâmico para a geografia escolar. É, na verdade, a tentativa de conversão, justaposição e sobreposição relacional desses temas com o movimento e o incentivo de construirmos esse pensar sobre a aula em campo, suas possíveis barreiras (que podem ser móveis) e as presumíveis capacidades pedagógicas. Assim, acreditamos que tratar da aula em campo é “comprar uma briga” temática, teórica e prática para nós, professores, que buscamos elucidar e romper com os exercícios pedagógicos engessados nas salas de aula e "dormentes" em relação à transformação das experiências socioespaciais dos estudantes.

Mesmo compreendendo que hoje grande parte da sociedade moderna mundial vive e acredita na 'verdade' das coisas construídas como 'novas', procuramos pensar a aula externa-interna fora dos impulsos mirabolantes. Admitimos, desde já, não trazermos nada de novo: nenhuma surpresa e nenhuma solução imediata para problemas que acreditamos já serem 'coisas velhas' no ensino de Geografia.

Para escrevermos e opinarmos sobre a aula em campo na geografia escolar, fez-se necessário voltarmos a alguns problemas de raiz: como a serventia da geografia, o conceito de aula e os papeis/relações que estudantes e professores podem assumir. E são por essas raízes, juntamente com as influências de autores como Thralls (1967); Monteiro e Oliveira (1988); Pontuschka (2004); Calvente (1998); e Oliveira (2006), que arriscamos fazer algumas considerações.

Nesse conflito criativo, o que se tenta escrever nesse texto é uma discussão que, frag- mentada e articulada em três momentos, busca compreender: as possíveis diferenciações entre o trabalho de campo e a aula em campo; os diferentes papéis e as questões teóricas que apresentam cada proposta para essa atividade externa à sala de aula; e as preocupações com o ensino de geografia, a vida externa (fora) da educação formal e os contatos que os alunos têm com as paisagens pelo senso comum do cotidiano capitalista.

Dando em seu bojo armas para que os estudantes venham se defender e problematizar suas práticas no fazer e ser (re)feito no/pelo espaço, nosso caráter mais secreto está em elucidar que "ser moderno é sentir-se compelido a enfrentar essas forças, a lutar para mudar o seu mundo transformando-o em nosso mundo" (Berman, 1986, p. 23). Buscamos, assim, (re)apresentar idéias que possam contribuir para a construção de olhares/práticas escolares além dessa noção de "ser moderno", contribuindo ainda na elaboração de materiais didáticos, nos quais se possam esquecer por alguns instantes (e nas estantes) os livro didáticos. Tudo isso pela tentativa de se reforçar que se faz necessário lembrar que devemos nos preocupar com a vida dos estudantes.

\section{Trabalho de campo e aula em campo: provocações para uma reflexão}

A aula em campo em nossa compreensão não é sinônimo de trabalho de campo, porém, a primeira só se torna possível de realização devido ao segundo, pois esta é uma etapa obrigatória do(s) professor(es) para que exista uma aula em campo: visitar o local; buscar dados e construir tabulações para análises prévias; realizar um esboço de construção de um percurso a ser seguido; fazer contatos iniciais com os diversos espaços estratégicos para con-

1. Para Berman (1986), ser moderno é ainda "encontrar-se em um ambiente que promete aventura, poder, alegria, crescimento, autotransformação e transformação das coisas em redor - mas ao mesmo tempo ameaça destruir tudo o que temos, tudo que sabemos, tudo que somos" (p. 11). 
dução da aula. Além disso, montar um banco fotográfico e documentar algumas entrevistas; problematizar já algumas dificuldades que possam vir a acontecer na realização do recorte escolhido, enfim, tudo isso faz parte do dito trabalho de campo (pesquisa) que acreditamos ser de fundamental importância para obter o potencial pedagógico da aula em campo. É nesse momento que teremos uma primeira, segunda e terceira racionalização daquilo que poderá vir a ser construído na aula. 0 trabalho de campo pode (deve) contar com a participação de alunos na elaboração, escolhas e leituras gerais da espacialidade a ser estudada. Muitas vezes, pode ser ele a realização de um projeto interdisciplinar na escola. Deve o trabalho de campo ser construído nesse movimento entre professores e alunos, entre a sala e o campo, constando, assim, como o primeiro momento da aula em campo.

A aula em campo é uma atividade extrassala/extraescola que envolve, concomitantemente, conteúdos escolares, científicos (ou não) e sociais com a mobilidade espacial; realidade social e seu complexo amalgamado material e imaterial de tradições/novidades. É um movimento que tende elucidar sensações de estranheza, identidade, feiura, beleza, sentimento e até rebeldia do que é observado, entrevistado, fotografado e percorrido. E ainda temos a certeza que essa aula não gera apenas isso. Eis alguns descaminhos antigos, difíceis, mas que podem ser corrigidos.

Instiga a aula em campo, antes de tudo, compreender as diferenciações entre as paisagens dos livros didáticos e as paisagens vivenciadas in loco. Estas são movidas e vivificadas pela relação dos alunos com as configurações óticas apreciadas sem recortes. São vistas juntamente com os movimentos das relações sociais, seus diferentes tipos de uso e seu entorno, a combinação de objetos naturais e artificiais - um instante da relação sociedade-natureza, ou melhor, das naturezas mais ou menos humanas - num verdadeiro conjunto de processos e objetos.

Partimos aqui do entendimento de que o campo sirva para despertar os alunos da passivi- dade, que o ensino-aprendizagem mais simplista tende a conduzir. Essa compreensão favorece 0 reconhecimento da aula em campo como instrumento de acesso ao binômio espaço/espacialidade, cujo movimento carrega, ao estudante, potenciais pedagógicos de facilitadores da elucidação do mundo pela geografia. Não se trata de uma substituição da sala pela 'rua', mas uma ligação do que é produto/produzido pelo aluno nas diversas escalas do particular - com o processo de mundialização que o orienta à condição de agir no espaço de diferentes maneiras, ajudando a construir a amplitude da aula, de tal modo a fazê-lo sentir e (re)agir sobre o seu próprio produto e além dele.

Grande parte dos alunos do Ensino Básico avança com algumas 'verdades' preestabelecidas. Estas são frutos de explicações geradas pela religião, pela mídia e pelos 'mitos' do senso comum, absorvidas como verdades no cotidiano. Dessa forma, uma educação que se diga geográfica na aula em campo, deve propiciar uma compreensão de recortes de mundo por meio do particular, facilitando nessas discussões uma capacidade de apreensão e um pré-entendimento sobre a totalidade que envolve combinações - econômicas, políticas, culturais, religiosas, artísticas e científicas - das práticas sociais no (re)produzir/fazer do espaço como necessidade da continuidade vital. Isso sem fugir das discussões do mundo capitalista e sua (re)produção de (re)codificação dessa realidade em segregação.

A aula em campo é um corpo didático que não tem como ser separado da sensação de lazer, ansiedade, angústia e novidades. Entretanto, não deixa de ser aula, requisitando, aos docentes e discentes, preocupação com o objetivo de estar em campo: uma construção e legitimação do pedagógico processo de formação humana dos alunos e dos próprios professores em sua trajetória profissional. A aula em campo não é um simples passeio, um dia de ócio fora da escola, o momento de alívio e brincadeiras, um caminhar para relaxar as mentes 'bagunçadas' das crianças e jovens do mundo moderno. 
Pensando nesses termos, Manoel Fernandes de Sousa Neto (2001) aponta:

A aula é processo e não produto; não é uma coisa com finalidade plenamente determinada, ainda que tenha um fim [...]. A aula, toda ela, todas elas, deve ser um ato de amor, uma dança. (p. 115-119)

Ainda inspirado no autor, apontamos que a aula é uma prática que deve ter em sua essência o processo metamórfico do trabalho intelectual no (re)fazer do professor e do aluno, já que ela é feita por ambos.

Nessa esteira, a aula em campo deve dançar no ritmo da relação de saberes problematizados na escola (livros didáticos, trabalho de campo, experiências etc.) e agora, movimentados na realidade 'viva', ela é esse próprio movimento. A escola e as forma pedagógicas de trabalharmos com os alunos a partir dos livros didáticos nem sempre contemplarão o que iremos ver no campo. Eis a necessidade do trabalho de campo para preencher essa possível lacuna. A ida ao campo sem o processo de contato/sensibilização por uma pesquisa anterior pode provocar, nos alunos, uma estranheza com o real sensível. 0 que levaria a classificarem aquilo que viram em sala quase como uma ficção, uma fantasia do real reproduzida em livros com imagens de outras regiões. Os livros didáticos tendem a produzir uma espécie de teoria capitalista em quadrinhos. Acabam encontrando condições de legitimarem suas ideologias diante da limitada condição de atuação (ou mesmo formação) de muitos professores. Orientar rotineiramente a leitura exaustiva de trechos do livro ou reproduzir questionários que confirmam os trechos lidos significa marcar a distância de um trabalho que se opõe à pedagogia da aula em campo.

Sobre a valorização e serventia da aula em campo e suas relações envolventes entre o dentro e o fora da sala, Silva (2006) argumenta:

A aula de [em] campo deve vir a complementar os conteúdos tratados em sala de aula, motiva ela o aprendizado, aprofundando o interesse pela pesquisa e favorecendo maior relacionamento entre alunos, entre alunos e professores, entre a escola e a realidade em estudo. Além disso, propicia avaliar a participação do aluno na leitura da realidade desenvolvendo o senso crítico, atitudes de responsabilidades e consciência do mundo em que vivem. (p. 12)

Compreendemos que a aula em campo atrelada à educação geográfica mais ampla, possa vir a contribuir intimamente na seleção de conteúdos trabalhados em sala, propiciando uma serventia para a vida dos estudantes no que diz respeito a suas práticas sociais, sua problematização de natureza e sociedade e seus ininterruptos movimentos na produção das espacialidades e do mundo. Construir práticas para a vida é talvez seu maior objetivo, práticas que não devem nunca se assumir como um mero caráter de utilitarismo imediato/passageiro. Muito menos afastar a possibilidade de construção utilitária de utopia no bojo das mais diversas necessidades humanas.

Buscar, dessa forma, uma seleção dos 'entulhos' estudados nas salas e retirá-los para construirmos novas práticas escolares - na relação aluno-professor na escola e fora dela - é também um desafio a ser enfrentado por nós, professores de geografia. Entendemos, assim, que a programação dos conteúdos deve estar densamente relacionada com um planejamento do calendário referente às aulas em campo. Torna-se impossível de aceitação na atualidade falar de um ensino de geografia sem o papel do trabalho dos alunos e professores em campo na sua formação, pois as aulas em campo buscarão sempre a reflexão e as possíveis quebras dos assuntos trabalhados (ou que possam vir a ser) em sala.

É preciso ainda frisar que a aula fora da escola sempre deve estar aberta para o desconstruir típico do impossível de ser planejado, o que chamamos aqui de imprevisível educacional, que é entendido como reflexão, incômodo, estranheza, barreira e experiência peculiar a cada aluno, sempre analisáveis como suporte para as inter- 
rogações das diferenciações de interpretações espaciais que acabam por mover os estudantes em suas práticas no lugar do/no mundo.

A aula em campo contempla a possibilidade de começarmos (ou continuarmos para alguns) a desmascarar aquilo que, às vezes sozinhos e sem objetivos, não conseguimos sequer enxergar. Ela nos possibilita a retirada de parte da sujeira que existe na casca de nossos olhos. É como se estivéssemos em um grande e escuro túnel fechado, mas com uma longínqua fissura, sendo a aula essa pequena claridade que adentra por essa fenda.

As discussões sobre essa atividade pedagógica, no ensino de geografia, não nascem nesse trabalho. Possuem uma história bem mais antiga que a própria geografia escolar em si, porém é a partir de meados da década de 1950, com algumas das traduções e produções acadêmicas para o ensino de geografia no Brasil, que faremos um breve comentário e algumas contribuições.

\section{Entre excursões, visitas, estudo do meio e turismo geoeducativo}

Pensar atividade extrassala, no que se refere ao ensino de geografia, não parece ser nenhuma novidade. 0 que se tem percebido com as leituras realizadas são as preocupações baseadas, principalmente, com as mudanças de propostas e fundamentações dessa atividade. Os diferentes olhares e o próprio entendimento do que essa atividade deve propiciar aos alunos e professores nos instigaram a discutir alguns autores que, influenciados por diferentes fundamentações filosóficas e metodológicas, levaram a construir ou apoiar tais linhas e objetivos que devem ser atingidos na aula em campo.

\section{Pensando as excursões a partir de Thralls}

A autora norte-americana Zoe A. Thralls escreve em 1967 o livro didático intitulado $O$ ensino de Geografia, que será traduzido no mes- mo ano para o Brasil pela Dalilla C. Sperb. Neste, a aula em campo é proposta nas intituladas excursões da comunidade com o objetivo de propiciar a leitura da paisagem local. Seria essa uma experiência direta de aprendizagem do aluno pela observação, dando a ele a curiosidade para compreender que relação a sociedade tem com o ambiente; estimulando o espírito de pesquisa e exploração por ele; contribuindo para que o aluno possa visualizar os aspectos das paisagens em outras áreas; interrelacionando a paisagem local com outros pontos do local, da cidade, do campo, do estado-nação e do mundo.

Para ela, faz-se necessário que os estudantes possam transformar o que leem na sala em compreensões empíricas.

Essa falta de habilidade da criança em transformar os símbolos da palavra em imagens ou conceitos parece originar-se, em parte, do ambiente restrito e da falta de contato significativo com o ambiente. (p. 126)

Dando continuidade, Thralls argumenta:

Muitos professores não compreendem que o ambiente das crianças é restrito. Isto acontece tanto à criança da cidade como a do campo. Muitas crianças da cidade nunca foram além de poucos quarteirões de suas casas. Nunca viram um aeroporto, depósito ou trem, ou uma plantação de milho ou de trigo. Não conhecem a atividade de arar, cultivar ou colher. Sabem, certamente, pronunciar as palavras com desembaraço, mas atrás das palavras não existem conceitos reais. A viagem ou a excursão, tanto na cidade como no campo, alarga a experiência da criança e ajuda-a na construção de significado. (p. 126)

Entendemos que a autora valoriza a observação/visualização em campo como ponto principal do trabalho. Discussões sobre textos e imagens observadas levam a uma relação entre aquilo que leem e visualizam e o que é 
experimentado na comunidade. A excursão tem esse recorte local: coloca em relação o aluno e o meio circundante da escola, observando suas paisagens, buscando entender que problemas existem nela e as construções feitas pelo homem sobre algum tipo de relevo. Para Thralls (1967), “a extensão do estudo da comunidade local quanto as suas relações nacionais e internacionais depende da maturidade do grupo" (p. 127).

A autora fragmenta e articula a organização de uma excursão em cinco etapas: 1) preparar-se a si mesmo (análise do professor sobre a excussão escolhida, a maturidade do grupo e o objetivo a ser estudado); 11) preparo pessoal do professor (estudo pelo professor dos aspectos naturais e culturais a serem observado nos roteiros, investigação de quem vai receber os alunos nos locais visitados, elaboração do mapa com o percurso, material necessário para ser levado pelos alunos e tempo da excursão); 111) preparo da classe (treinamento da observação para a excursão com a discussão do objetivo, os enclaves que a atividade pode gerar e avaliação do roteiro feita pelo professor); IV) direção da excursão pelo professor (controle permanente, porém sem criações de problemas insignificantes e deve manter contato constantemente com todo grupo); e V) atividades pós-excursão (exemplos: elaboração do sumário para o relatório escrito, servindo na elaboração de um programa de auditório, apresentação em rádio e televisão, um folheto ou artigo de jornal, momento da avaliação da turma e do professor).

A autora põe em questão ainda a necessidade de trabalharmos com as técnicas de cartografia e os dados em sala de aula, para que as leituras feitas nas excussões possam ser mais esclarecedoras do que as interpretações das tabelas, cartas etc.

\section{As visitas para Oliveira e Monteiro}

Didáticas dos Estudos Sociais, de Maria Helena Cozzolino de Oliveira e leda da Silva Monteiro, produzido em 1988, é um dos escritos que contribui para se refletir acerca das atividades extrassalas no que se refere ao en- sino de geografia. Cabe aqui frisar que o momento no qual ocorre a produção bibliográfica verifica-se um atrelamento da disciplina de Geografia ao ensino de História, conforme o conjunto disciplinar conhecido anteriormente como Estudos Sociais, que foi uma das marcas curriculares da Política de Educação Básica da Ditadura militar que, por intermédio das Leis 5540/68 (Reforma Universitária) e 5692/71 (Ensino de $1^{\circ}$ e $2^{\circ}$ graus), implantou a licenciatura curta nessa categoria formativa em substituição às formações específicas de profissionais de Geografia e História. Essa disciplina passou a desaparecer na década de 1980 e, definitivamente, pela promulgação da LDB 9394/96.

Monteiro e Oliveira (1988) trabalham com as visitas como atividades extraclasses que estão relacionadas ao ensino de geografia e história. As autoras citam outras contribuições além das já levantadas por Thralls (1967). Para elas, as visitas também proporcionam aos alunos ter diferentes hábitos e atitudes de comportamentos em diferentes ambientes, oferecendo as possibilidades de descobrimento de novos valores e novas relações, enriquecendo e ampliando suas experiências.

Compreendemos que as autoras trazem o termo visita como uma aula em campo que possa vir a acontecer na comunidade e além desta. A excursão poderá destinar-se a uma empresa ou a algum órgão governamental. 0 que apresenta mesmo nas entrelinhas o deslocamento por meios de transporte e um afastamento da realidade do aluno e da comunidade escolar.

Para as autoras, a escola corre o risco de construir para os alunos uma muralha de isolamento que os separem das realidades concretas e da labuta humana.

As visitas rompem essa muralha de isolamento e lhes permitem observar e sentir essas realidades, para as quais se preparam pela disciplina e pelo estudo, ampliando sensivelmente o raio de seus conhecimentos e de sua experiência. Constituem, portanto, um ingrediente indispensável na formação das novas gerações (Monteiro; Oliveira, 1988). 
A preocupação das autoras é, sem dúvida, 'rasgar' os muros de 'reclusão' do aluno, isto é, a sala de aula, muitas vezes concebida como responsável por toda a aprendizagem do conhecimento. 0 ímpeto está em alertar para os alunos que se faz necessário treinar os olhares sobre as diversas paisagens, descrevendo-as na construção de um relatório, que servirá como avaliação e análise do que foi discutido em sala e tornandose complemento do estudo efetuado.

Nota-se nessa bibliografia que o olhar aparente da realidade, a partir das visitas, servirá para que cada aluno construa sua liberdade de pensar ao atentar nos livros didáticos e no cotidiano. A observação servirá, para as autoras, como uma atividade de sistematização e contato dos estudantes com as totais dimensões da entendida realidade.

\section{O estudo do meio pelos olhares de Pontuschka e Calvente}

0 estudo do meio também tem sido uma das denominações e proposta de aula em campo para as disciplinas escolares. Em escrito intitulado $O$ conceito de estudo do meio transforma-se..., Nídia Nacib Pontuschka (2004) mostra como as metamorfoses fundamentais desse conceito acompanham os contextos históricos pelos quais passaram as escolas e, assim, o ensino. Cita como um dos exemplos as Escolas Anarquistas que, nas primeiras décadas do século $X X$, entendiam o estudo do meio como instrumento de formação humana na criação da capacidade de crítica à vida de submissão.

Os trabalhos realizados fora da sala de aula por tais escolas tinham como objetivo que os alunos, observando e descrevendo o meio dito natural e o social do qual faziam parte, pudessem refletir sobre as desigualdades e as injustiças (Pontuschka, 2004), diferentemente das escolas 'novistas', de 1945-1965, que vão entender o estudo do meio como potencialidade pedagógica que "permite vivenciar a realidade como um todo em que os elementos estão estruturados", todo que, na sala de aula, acabam encontrando- se "compartimentados em geografia, história, biologia, artes etc.” (p. 254), fragmentado-se em matérias escolares quase que incomunicáveis no quadro escolar.

Para ela, o que vem acontecendo é que o estudo do meio, nos dias atuais, serve de roupagem às diversas atividades.

Desde uma saída de alunos e professores cujo objetivo, principalmente, seja o entretenimento até trabalhos interdisciplinares que demandam pesquisas de campo, bibliográfica, corográfica, e, portanto, investimento em trabalho individual e coletivo. (p. 249)

A autora compreende que o estudo do meio não é passeio nem muito menos algo destituído de planejamento. É um método de estudo interdisciplinar para as atividades extrassala, tendo a geografia o papel de elucidar para os alunos a importância e as significações do espaço geográfico.

0 meio é uma geografia viva. A escola, o córrego, a população de um bairro, o distrito industrial, um parque, uma reserva florestal, um shopping, um hipermercado, a chácara vizinha são elementos integrantes de um espaço, que podem ser pontos de partida para uma reflexão. Em um primeiro momento, pode-se descrever utilizando os referenciais vivos para localizá-los. No entanto, é preciso ir além. Em qualquer lugar escolhido para realizar um estudo do meio, há o que ver, há o que refletir em geografia, pois não existem lugares privilegiados, não há lugares pobres. É preciso saber ver, dialogar com a paisagem, detectar os problemas existentes na vida de seus moradores e estabelecer uma relação entre os fatos verificados e o cotidiano dos alunos (Pontuschka, 2004).

Finalizando, a autora destaca o importante papel que o estudo do meio deve gerar na volta à sala em relação à elaboração de material didático para a escola e a comunidade visitada, construindo nessa etapa um arquivo/arcabouço constituído de conhecimentos a respeito das diversas espacialidades que foram estudadas, tendo ainda a produção de relató- 
rios de campo, de arquivos e exposições fotográficas e a organização do conjunto de entrevistas como trabalhos de avaliação.

Outro escrito nomeado $O$ conhecimento, o meio e o ensino de geografia, de Maria Del Carmen M. H. Calvente, que compõe juntamente com outros escritos o livro Para quem ensina geografia, publicado em 1998, também tem como discussão o estudo do meio. Para a autora, o meio é entendido como

\section{[...] a concretização das forças que regem o mundo atual. É a partir do meio que se pode perceber a obra dos homens no tempo e no espaço e perceber-se como sujeito. (p. 90)}

A proposta do estudo do meio é trazer uma situação concreta de existência como um problema que desafia e exige respostas não apenas intelectuais, mas de ação. Nessa mesma esteira, pensa-se a interrelação das coisas físicas e humanas na construção do meio: "um rio poluído pode levar a industrialização, à migração, à questão agrária e a história da vida de cada um” (Calvente, 1998, p. 89).

Para a autora, o laboratório de geografia é a própria realidade. Por isso, acredita que o estudo do meio oferece oportunidade para tal apreensão do mundo concreto, construída socialmente em suas múltiplas dimensões e inter-relações.

0 meio é composto por elementos e fenômenos sociais e naturais. Entende-se que o homem também é natureza - natureza que criou consciência de si própria e organizou-se para a vida em sociedade. Nas relações da sociedade humana entre si e com um determinado território, principalmente nas últimas décadas, impactos negativos, principalmente as poluições (do ar, da água e do solo), passaram a ser denominados de questão ambiental. Frente ao materialismo histórico, os fenômenos naturais nunca são explicados em si mesmos, mas o são como recursos para a vida humana, tendo o trabalho como elemento mediador. 0 relacionamento do homem com o ambiente é resolvido dentro de relações sociais historicamente determinadas (Calvente, 1998).
0 estudo do meio está atrelado diretamente aos níveis e tipos de técnicas (meios) que levaram a tal comunidade, bairro, município, estado e nação a transformar o espaço geográfico no tempo. Entender em campo alguns dos elementos (re)produtores do espaço em sua totalidade é aqui um de seus desafios. Esse estudo extraclasse tem como metodologia elaborar e realizar entrevistas no meio visitado, buscar pesquisar se essa área em destaque está tratada em livros didáticos, construir croquis dos locais visitados e dos outros locais que esse espaço tem relações, pondo assim em mapas as possíveis comunicações etc.

\section{O turismo geoeducativo conforme Oliveira}

Um último estudo que aqui analisamos refere-se ao trabalho de Christian de Oliveira (2006) intitulado Do estudo do meio ao turismo geoeducativo: renovando as práticas pedagógicas em geografia, escrito que tem como objetivo atualizar o que se chama de estudo do meio para turismo geoeducativo.

Para Oliveira (2006), o estudo do meio realizado por muitas escolas está fadado às idealizações, às utopias, ao não cuidado de práticas destoantes do próprio meio vivido. 0 estudo do meio, segundo o autor, abre-se para a

\section{[...] incorporação de saberes espaciais não científicos, densos de significação cultural e ambiental [e fecha-se] à força retórica de uma geografia que quer generalizar realida- des em escala-mundo, discutindo os espa- ços locais apenas como subprodutos de uma 'unidade' global. (p. 33)}

0 autor critica o planejamento de termos a aula em campo somente como um complemento ou comprovação do que foi visto em sala. "Isso é de uma pobreza quase infinita, mas é a regra geral em vigor” (Oliveira, 2006. p. 35).

A forma clássica e programada do estudo do meio, interpretado pelo autor, é quase que uma maquiagem educativa, resumida a pontos e 
guiada muitas vezes pelos livros didáticos e agências de turismo. Pode-se depreender dessa crítica uma correlação entre as práticas do turismo de massa e a visão preestabelecida de uma didática que aquele meio a ser estudado (e não outro) possa proporcionar para garantir a aprendizagem de determinados conteúdos: como as serras, as zonas de praia, os centros históricos, os parques nacionais, os chamados monumentos patrimoniais etc., afastados da comunidade e da própria escola, do comprometimento de mudança daquilo que os alunos e a sociedade vivem. 0 meio aí se limitaria a um lazer despertado pelas viagens mirabolantes mercadológicas que reproduz quase sempre o resultado esperado. Por isso, propõe uma mudança de conceitos e de práticas pedagógicas. Oliveira (2006) aponta que

0 Turismo Geoeducativo permite aos estudantes uma prática de diálogo com os lugares, fazendo-os interagir com atrativos e repulsivos (aqueles elementos que no Turismo retórico não devem ou não podem ser observados). Não busca os lugares em si, como se estes formassem paisagens neutras ou desocupadas. Busca a possibilidade de interação sócio-ambiental constante; mesmo em sua forma invisível ou indireta. [...] Não é um turismo que se pauta pelos gastos fornecidos para cada hóspede visitante [...] torna-se necessário repensar o processo moderno do Turismo como algo também enraizado na cultura social humana. (p. 44-45)

Construir objetivamente uma relação sociedade-ambiente entre alunos e professores, com comunidades escolares de diferentes potenciais para visitas e dispostas a interagirem nas atividades de campo, assume ser o compromisso do turismo geoeducativo.

\section{Aula no campo: reflexões para as velhas preocupações}

A formação de diversos pensamentos sobre a aula fora da sala expressa a importância que essa atividade assume perante o ensino de geografia. Avaliamos que as elaborações objetivas das atividades extrassala, nas discussões entre os autores, se cruzam e se afastam em diferentes pontos detalhados. Isso ocorre devido aos fundamentos filosóficos nas próprias metamorfoses do ensino e correntes de pensamento escolhidas por eles, contando ainda, sem menor interferência, com as mudanças no espaço-tempo de cada autor vivenciado. No entanto, exaurir a questão não é nosso objetivo nesse momento. Nossa preocupação, centrada na reunião das diversas reflexões, é o incentivo a reelaboração pedagógica da aula em campo, em sua prática de retorno à sala de aula. Nesse retorno, concentraremos a parte final desse trabalho.

A aula em campo, amiúde, reprime os objetivos traçados pelo trabalho de campo. Isso porque essa atividade consta com uma dinâmica entre alunos e professores, comunidade/sociedade e locais visitados que acabam por fazer dela uma espécie de dança imprevisível na interação desses agentes.

Em nossa compreensão, a atividade de retorno à sala de aula completa aquilo que no campo escapou, ficou subentendido ou malentendido. Ela ultrapassa o momento de reunião das entrevistas, fotografias e a narração das melhores vivências. Não se esgota com a simples 'avaliação', na qual uma turma afirma ter sido ótimo 'ver' a 'realidade'. 0 voltar para sala gera a oportunidade de os professores de introduzirem as seguintes questões:

- Que imagens, paisagens, grafias foram interpretadas pelos alunos na aula em campo?

- 0 que gerou essa interpretação?

- Será que paisagens semelhantes foram interpretadas por diferentes alunos como a mesma paisagem?

- Que tom de unidade envolve os alunos para criar coisas diferentes mentalmente e viver em um mundo de entendimento harmonioso?

- Como enxergar, com o aluno, além do que aprendemos a ver?

- Como buscar, a partir da aula em campo e da 
(in)formação do aluno, as mudanças necessárias dos conteúdos que 'ensinamos' em sala?

- Como avaliar se sua realização foi completa?

- Como distingui-la como necessária ou enganadora?

- Qual a melhor forma de assegurar sua reedição?

A primeira fase dessa problematização foi realizada em campo. Pautou-se na lembrança de que o aluno, tão mencionado, é sujeito portador de ações, e que suas opiniões/decisões permeiam o tecido social concreto de seu mundo.

Envolvido em um amálgama político, cultural e ambientalmente amplo, o estudante tende a construir, como ente intersubjetivo, diferentes valores e saberes, espelho das mesmas ideologias do capitalismo cotidiano, que são coerentemente objetivas e perversas por sua natureza social. Como resultado desse enfrentamento: o estudante vivencia em sua prática a necessidade de converter escalas extremas (local e global) em processos simultâneos de inserção na geografia do real e do virtual, construindo dessa maneira uma educação geográfica.

Eugênio Trivinho (2007) denomina esse processo de glocalização. Termo que designa a simultaneidade de diferentes globalizações em cada localidade, afastando assim a idéia de que os lugares sejam predominantemente vítimas dos processos globais. Compreende que é este o principal desafio contemporâneo das civilizações para conectarem-se às mudanças virtuais do ciberespaço hodierno: encontrar as forças globais na densidade (real-virtual) das localidades. Visto como uma convocação, tal processo multiplica a necessidade de atenção dos educadores ao fluxo das práticas nos lugar no tempo presente.

Então, se para nós as reflexões pedagógicas estudantis e professorais devem fluir desse presente (mesmo sabendo que não o resumem), o que se deve saber-fazer com as "construções imagéticas" que os estudantes apreenderam fora da escola? Se a aula em campo conduz o reencontro da criança com um empírico, compreendemos que a volta à sala requer dos professores e alunos a capacidade de reconstituir o que viram socialmente em aprendizagem e leitura geográfica do(s) local(is) estudados. Na leitura desse mundo de formas e relações e além de formas símbolos, muita das interpretações e conteúdos que são construídos pelos alunos diferem. Isso tanto na codificação de conteúdos geográficos e históricos, bem como nos significados no contexto da totalidade de seu local (para que e quando servem). Por isso, é de suma importância que se pense na volta a sala de aula as "estratégias-didáticas" para buscarmos os significados que foram dados aos objetos naturais, edificados, e ao movimento da sociedade pelos alunos.

De modo sintético, para Tharlls (1967), as excursões devem abranger a observação na construção de símbolos da realidade para o melhor entendimento das leituras - e a técnica; Monteiro e Oliveira (1988) valorizam a observação para a percepção de novos valores e novas relações no quebrar dos 'muros' das escolas pelas visitas; Calvente (1998) e Pontuschka (2004) buscam no estudo do meio o entendimento das forças que regem o mundo na concretização e configuração do próprio meio geográfico, na qual exige respostas intelectuais e práticas na produção do espaço no tempo; sendo que Oliveira (2006) levanta um pensamento de aproveitamento e comprometimento com os lugares a partir do turismo geoeducativo. Admitimos aqui não queremos criar uma nova denominação para a atividade extrassala, já que concebemos que os estudos ajustam-se e sobrepõe-se, aproximam-se e afastam-se. 0 que se requer insistir é que a aula em campo exige o retorno à sala de aula como uma etapa de finalização e reinício do processo.

Para isso, propomos uma atividade que poderá ser aproveitada como motivos para avaliação, elaboração de material didático e descobrimento dos "segredos" dos alunos em que nós admitimos ser os professores. Chamamo-la de autobiografia coletiva da aula anterior.

A autobiografia coletiva não é aqui sinônima de relatório, muito menos de descrição. Ela é uma releitura narrativa e interpretativa dos 
alunos sobre as suas histórias e o que a aula exterior chegou a marcar em cada um. Construir croquis com as belezas, as feiuras, as formas, as pessoas, inserir as fotografias e as entrevistas coletadas em campo é um bom sumário/caminho para chegarmos a uma interpretação acessivel de quais imagens os estudantes associaram como belas e/ou feias.

A partir dela, teremos a oportunidade de buscarmos as histórias do empírico, das paisagens (sejam fachadas, relevos, rios, edifícios, currais, plantações, assentamentos rurais, centros históricos etc.) como, e principalmente, daquilo que nós não enxergamos completamente em cada história dessas, isto é, o invisível de cada coisa que está em constante mudança como o próprio significado e as funcionalidades das formas. Devemos, como docentes, aproveitar as discussões das autobiografias como momento para efetuar difíceis, mas necessárias, 'demolições' de paisagens indiretamente registradas, documentadas e narradas apenas nos manuais. A autobiografia coletiva resultante desse embate pedagogicamente geográfico não poderá ser realizada sem uma devida discussão, problematização e encaminhamentos para outras práticas sócioespaciais.

Nessa perspectiva, a autobiografia coletiva também nos possibilita certa arte para varrer entulhos (conteúdos) de duvidosa serventia, seja à aula ou ao aluno. Qualificar a potencialidade dos sonhos discente é propor interrogações substanciadas em suas práticas sociais (escola, lazer, festas, vivências...) e tecer uma educação geográfica nos conflitos da natureza social. É e será, por um longo tempo, uma responsabilidade docente reger também essa volta à sala de aula para reconstruir isso.

A conexão da geografia escolar com o que está fora da escola, partindo desse movimento da localidade e dos lugares das práticas sociais dos estudantes ${ }^{3}$ às forças políticas, econômicas e culturais que movem o mundo onde estamos, mostra uma discussão do vivido adjunta à totalidade que possibilita interrogar o ir/ sendo estudante e professor nas metamorfoses da escola e da cidade. Em função dessa análi- se, poderá compor o caráter metodológico a própria estabilidade permanente no que se refere ao uso do ensino da geografia para a transformação do que é visto/interpretado pelo estudante em sua prática espacial. A geografia pode servir para fazer uma outra leitura da vida. Acreditamos no embate deste com demais processos hegemônicos, o que requer um exercício mais racional de cautela e cuidado. 0 que não barra o fazer de fato. Tudo é construto coletivo: um forjar intimidades entre estudantes $<=>$ professores $<=>$ cotidiano. No entanto, nada mais necessário que nossa prática pedagógica além das normas para educação.

Em suma, a proposta do externo aponta para discussões, envolvendo a sala de aula e construção autobiográfica. Valida, portanto, novas ‘saídas' para o campo de novidades, tradições e imprevistos nas sucessivas mudanças dos coletivos sociais. Deixar em aberto outras criatividades que possam complementar essa capacidade de irmos construindo outro currículo/prática escolar de acordo com a dinâmica da realidade, também, faz parte dessas últimas palavras.

\section{Para (não) concluir}

No filme A língua das borboletas (La Lengua de las Maripozas, 1986), de José Luis Cuerda, o professor Don Gregório pergunta para os alunos em sala: vocês gostam da natureza? Os alunos não conseguem se quer ter uma opinião, uma formulação do que a natureza natural (a chamada natureza dada para Lefebvre, 1975) proporciona para a vida, quais os segredos ela esconde e que compromissos devemos ter com ela. Durante a primavera, Don Gregório ministra uma aula em campo, os alunos parecem viver e está aprendendo outras coisas além do previsto, parecem sentir medo e estranhar o campo. Abrem sorrisos tortos, tocam uns

3. No caso das escolas públicas em Fortaleza, grande parte dos estudantes mora no bairro em que está localizado a própria escola na qual faz parte. Construir aulas em campo nessa forma de organização educacional-espacial muitas vezes contribuem para a facilitação dessas atividades extrassalas e dinamizações. Falta muita vezes a formação do professor ou mesmo a compreensão do que se pode fazer fora da escola. 
aos outros, parecem mostrar escutar outras coisas além do que o professor Gregório exclama. Todavia, a explicação iniciada sobre a tão esperada, planejada e ideológica língua das borboletas é esquecida devido ao grito desmantelador de uma das crianças: "olha aqui um formigueiro!" Todas correm em direção ao garoto. A explicação do desenrolar da língua das borboletas em busca do néctar na flor já não era mais possível.

Muitas vezes, durante a aula em campo, o imprevisto poderá mudar todo o rumo esquelético e explicativo do programado. Eis uma das riquezas que ultrapassa os livros didáticos, o planejamento, as avaliações prévias, criando as chamadas novidades que devem ser trabalhadas na volta à sala. Acreditamos que as atividades, no coletivo desse retorno e organizadas a partir dos relatórios construídos, levem à prática das socializações das novidades e, particularmente, no momento da construção da autobiografia coletiva e do que ela possa vir a representar para o local visitado que vivemos em sua interferência mundial.

0 papel do professor jamais poderá ser neutro ou ilimitadamente flexível nessa etapa de discussões sobre o pequenino 'borrão' construído pelos alunos. Estamos em um período de relações sociais bastantes valorizadas pela imagem, numa criação constante e fugidia de belezas e feiuras, de valorização e desvalorização das necessidades, retocadas pelo invólucro democrático (ou dromocrático) ao qual já nos referimos. E nessa esteira ideológica, não podemos corroborar, simplesmente, com um aluno quando ele fala que as

\section{[...] avenidas centrais de nossas cidades} grandes são belas, maiores que as ruas de nossas periferias... pois os centros financeiros ou turísticos têm edifícios, limpezas, imagens coloridas, vidros, turistas e grandes restaurantes.

Faz-se necessário que o professor analise com cuidado, calma e respeito a opinião do coletivo discente. Não se pode ser 'chato' ao extremo (a pedagogia requer paciência) nem dar o grito libertário como se a amanhã de aula fosse um outubro moscovita de 1917, imaginada para fora da janela. No entanto, é fundamental que o aluno descubra, com o auxílio dialógico do professor, um pouco da crítica que as aparências cobram do seu olhar, para que brilhem com aparências de fato, como a ilusão ilustrativa de um capitalismo insuficiente.

Os significados envolvidos entre o olhar em campo, a criação dessa imagem pelo aluno e o que a geografia pode contribuir para uma contraocultação do aparente é, sem dúvida, uma das tarefas a serem materializadas nas discussões. Talvez seja um caminho diferente para a construção de uma educação geográfica transcendente aos limites da cidadania, posto que, muitas vezes, o papel e o discurso geográfico têm favorecido um conjunto de riquezas mitológicas, reduzindo o cidadão a um ser conformado e pronto para conviver de imagens: as mais 'absurdas' como beleza; a eminência do fim como a realização dos sonhos; e o jogar copinho no lixo como a saída para a criação de outro modelo de ethos ambiental. Uma coleção de vazios!

Precisamos perguntar, em nossa convivência profissional com o aluno, coisas além do que ele vai ser quando crescer, que profissão gostaria de exercer na sociedade e que países ele sonha conhecer. Deixar claro que são crianças, jovens... bem jovens. Apertar as mãos dos alunos e dizer que se eles estudarem vão se dar bem quando crescer não constitui práxis dialógica alguma. Lembramos nesse momento de uma poesia de Carlos Drummond de Andrade e acreditamos na ajuda que ela poderá nos doar para nós, professores, preocupados e interessados em buscar sempre melhores condições para a formação do ser humano-estudante.

VERBO SER Que vai ser quando crescer? / Vivem perguntando em redor. Que é ser? / É ter um corpo, um jeito, um nome?/ Tenho os três. E sou?/ Tenho de mudar quando crescer? / Usar outro nome, corpo e jeito? / $\mathrm{Ou}$ a gente só principia a ser quando cresce? /É terrivel, ser? Dói? É bom? É triste? / Ser; pronunciado tão depressa, e cabe tan- 
tas coisas? / Repito: Ser, Ser, Ser. Er. R. / Que vou ser quando crescer? /Sou obrigado a? Posso escolher? / Não dá para entender. Não vou ser. / Vou crescer assim mesmo. / Sem ser Esquecer.

Nessa perspectiva, ratificamos a importância de insistirmos que se faz necessário "enxergarmos além do que aprendemos a ver", quer para os alunos quer para os professores. É uma bataIha que se inicia com a sala de aula e seu apoio ao trabalho de campo, a aula em campo e seu retorno ao movimento anterior na própria sala, construindo pelas faíscas das "paisagens discentes' aquilo que chamamos de autobiografia coletiva. 0 esforço de ambos os sujeitos, na busca de uma compreensão além do que se vê - praça, favela, assentamento, estradas, ferrovias, fábrica ou monumentos - estará permanentemente no alvo dessa produção pedagógico-geográfica.
Torna imprescindível o compromisso social de cada um com o lugar, com a cidade ou o campo e, consequentemente, com o mundo. Não estamos aqui transportando as responsabilidades de cada localidade, exclusivamente, para os habitantes, mas, ao contrário, enxergamos nessa mudança a possibilidade de construirmos um cidadão descolado da cidadania morta (planejada para a continuação da aceitação e conformação a tudo) da atual democracia brasileira. Queremos finalizar com dois quereres: primeiro que se faz necessário pensar/reforçar o entendimento construção/formação de estudantes e professores que entendam cultura e política como a arte de definir diversas dimensões de limites, bem como, de extrapolar limites; e segundo, fica evidente que nossa vontade última é construir uma geografia que em vez de cegar as crianças, esclareça a importância da apropriação do espaço na vida social. 


\section{Referências bibliográficas}

BERMAN, M. Tudo que é sólido desmancha no ar. São Paulo: Companhia das Letras, 1986.

CALVENTE, M. D. C. M. H. 0 conhecimento, o meio e o ensino de Geografia. In: CARVALHO, M. S. de. (Org.). Para quem ensina Geografia. Londrina: UEL, 1998. p. 82-102.

CUERDA, J. L. La lengua de las mariposas. Espanha: Sociedad General de Cine; Las Producciones del Escorpión, 1999.

OLIVEIRA, C. D. M. de. Do estudo do meio ao turismo geoeducativo: renovando as práticas pedagógicas em Geografia. Boletim Goiano de Geografia, v. 26, p. 31-47, 2006.

OLIVEIRA, M. H. C. de; MONTEIRO, I. da S. Didática dos estudos sociais: como aprende - como ensinar. 4. ed .São Paulo: Saraiva, 1988.

PONTUSCHKA, N. N. O conceito de estudo do meio transforma-se... em tempos diferentes, em escolas diferentes, com professores diferentes. In: VESENTINI, J. W. 0 ensino de geografia no século XXI. Campinas: Papirus, 2004. p. 249 -288.

SANTOS, M. Metamorfoses do espaço habitado. 4. ed. São Paulo: Hucitec, 1996.

SOUSA NETO, M. F. A Aula. Geografares, Vitória, n. 02, jun. 2001. p. 115-120.

THRALLS, Z. A. 0 ensino da Geografia. Porto Alegre: Globo, 1967.

TRIVINHO, E. A dromocracia cibercultural: a lógica da vida humana na civilização midiática avançada. São Paulo: Paulus, 2007.

Recebido em 03.08.08

Aprovado em 20.02.09

Christian Dennys Monteiro de Oliveira, doutor em Geografia Humana (USP), é professor adjunto da Universidade Federal do Ceará e pesquisador do Núcleo de Avaliações em Políticas Públicas e do Laboratório de Estudos Geoeducacionais.

Raimundo Jucier Sousa de Assis é graduando em Geografia pela Universidade Federal do Ceará, participante do Laboratório de Estudos Agrários e Territoriais do Departamento de Geografia da UFC e é professor do Pré-Vestibular Popular da Prefeitura de Fortaleza (POPFOR). E-mail: juciersousa@yahoo.com.br 